\title{
ZONEAMENTO HIERÁRQUICO DA PAISAGEM NOS DOMÍNIOS DA BACIA DO RIO URUGUAI
}

\section{Landscape hierarchical zoning in the domains of the Uruguay River Basin}

Marcos Wellausen Dias de Freitas Instituto Nacional de Pesquisas Espaciais, São José dos Campos, São Paulo, Brasil. marcoswfreitas@gmail.com

João Roberto Santos Instituto Nacional de Pesquisas Espaciais, São José dos Campos, São Paulo, Brasil. jroberto@dsr.inpe.br

Artigo recebido em 19/11/2012 e aceito para publicação em 21/02/2014.

RESUMO: Este artigo apresenta uma abordagem que combina ferramentas de Sistemas de Informações Geográficas (SIG) e de Sensoriamento Remoto (SR) para o mapeamento integrado da paisagem, dentro de diretrizes de um zoneamento hierárquico e de princípios da Ecologia da Paisagem. Variáveis físicas, ecológicas e sociais são integradas, empregando-se análise multivariada desses fatores para uma categorização de unidades de paisagem. Na abordagem metodológica constam as fases de: a) organização e processamento das variáveis paisagísticas em ambiente de SIG e de Análise de Imagem Orientada a Objetos Geográficos (GEOBIA); b) zoneamento hierárquico da paisagem em "geons" e Unidades de Planejamento da Paisagem (UPP's); c) análise multivariada das UPP's resultantes com a definição de dois níveis hierárquicos (hólons) da paisagem. O mapeamento das unidades de paisagem e a análise multivariada permitem o entendimento de padrões e da distribuição espacial da paisagem investigada. O zoneamento hierárquico da paisagem aqui desenvolvido traz uma contribuição da abordagem de GEOBIA, considerado potencial para a análise e integração de dados de SIG e Sensoriamento Remoto nesse tipo de estudo.

Palavras-chave: Ecologia da Paisagem, Análise de Imagem Orientada a Objetos Geográficos, uso e cobertura da terra, dinâmica da paisagem.

ABSTRACT: This work presents an approach based on the combination of Geographic Information Systems (GIS) and Remote Sensing (RS) tools for the landscape integrated mapping within hierarchical zoning guidelines and Landscape Ecology principles. Physical, ecological and social variables are integrated using the multivariate analysis of these factors to the categorization of landscape units. The methodological approach included the following stages: a) landscape variables organization and processing in a GIS and object-oriented based image analysis (GEOBIA) environment; b) landscape hierarchical zoning in landscape "geons" and Landscape Planning Units (UPP's) c) multivariate analysis of the UPP's result with the definition of two landscape hierarchical levels (holons). The landscape units mapping and multivariate analysis allows the understanding of the spatial distribution and patterns of the investigated landscape. The landscape hierarchical zoning developed here brings a contribution of the GEOBIA approach considered potential for analyzing and integrating GIS and Remote Sensing data in this kind of study.

Keywords: Landscape Ecology, Geographic Object-oriented Based Image Analysis, land use and land cover, landscape dynamics. 


\section{INTRODUÇÃO}

O planejamento territorial necessita do suporte de análises baseadas em dados espaciais para a formulação eficaz de estratégias, visto que na análise da problemática socioambiental faltam estudos, por exemplo, de prevenção referente a desastres naturais, de zoneamento de ocupação e análise da dinâmica de uso da terra e de estudos sistemáticos de impactos ambientais, dentre outros, para uma efetiva e eficaz definição de políticas públicas. Para isso acontecer, há necessidade de se dispor de dados socioambientais regularmente atualizados e ferramentas de aquisição e tratamento de dados que permitam a manipulação técnica, dentro de um contexto de compatibilização que permita análises integradas em relação aos elementos naturais e da atividade humana na paisagem.

A aplicação de geotecnologias na tomada de decisões ligadas ao ordenamento territorial e à gestão ambiental tem apresentado diversas potencialidades relacionadas à capacidade de aquisição, organização e análise de dados espaciais. E dentro desse contexto, o objetivo deste trabalho apresenta uma análise teórica e aplicada desse ferramental de mapeamento integrado da paisagem, tendo enfoque: a) na regionalização de um zoneamento hierárquico da paisagem, integrando variáveis físicas, ecológicas e sociais; b) na análise multivariada desses fatores físicos, ecológicos e sociais para a definição e classificação de unidades de paisagem.

\section{SÍNTESE TEÓRICA}

$\mathrm{Na}$ ecologia da paisagem, um conceito importante é o de geossistemas, criado na escola geográfica russa por Sochava (1977), que se baseia na compreensão global da paisagem em seus elementos físicos, ecológicos e sociais e seus intercâmbios de matéria e energia (ROUGERIE; BEROUTCHACHVILI, 1994; SILVA, 2007; FREITAS, 2009). Outras escolas geográficas se inspiraram nessa abordagem geossistêmica russa e desenvolveram metodologias para estudos integrados da paisagem, com conceitos adaptados às peculiaridades de seus próprios países, como na França (TRICART; JONGE, 1992; BERTRAND; BERTRAND, 2002), Holanda (ZONNEVELD, 1989) e mesmo do Leste europeu (HAASE, 1986).
No Brasil, as principais contribuições com foco nos geossistemas vieram de Monteiro (2001), ao buscar a aplicação de metodologias integradas de análise da paisagem para: a) estudar a relação entre a natureza e a sociedade na formação da paisagem, b) efetuar a tomada de decisões em nível de planejamento territorial e gestão ambiental, c) subsidiar a modelagem de sistemas ambientais que permitam a geração de cenários e prognósticos da paisagem. Contudo, Apesar das diversas denominações existentes de acordo com respectivas escolas (ecossistemas, geossistemas, unidades de paisagem, unidades geoambientais, unidades territoriais básicas, unidades homogêneas, sistemas de paisagem, geocomplexos, etc.), todas apresentam uma base convergente a respeito da necessidade de uma compreensão integrada entre o homem e a natureza, para uma aplicação eficaz de políticas de planejamento territorial (MONTEIRO, 2001). Em relação à denominação de unidades de paisagem, esse autor propôs a utilização da noção de hólon de Koestler (1969) para a caracterização da hierarquia da paisagem.

$\mathrm{Na}$ definição de metodologias de análise e mapeamento integrados da paisagem, devem-se levar em consideração as diferentes demandas sociais e ambientais referentes às condições de resiliência da paisagem na tomada de decisões, sobretudo àquelas ligadas aos projetos de planejamento territorial e de previsão de impactos socioambientais (HAASE, 1986). Adaptações metodológicas podem ocorrer de acordo com a natureza e complexidade da paisagem a ser mapeada e aos objetivos a serem alcançados, respeitando pontos de vista múltiplos, de cunho analítico e sintético, no decorrer da elaboração dos métodos e pensamentos interpretativos.

O método principal de mapeamento de unidades de paisagem com base nas ferramentas de Sensoriamento Remoto (SR) e Sistemas de Informações Geográficas (SIG) no Brasil é o das Unidades Territoriais Básicas (UTB's) contido nos projetos do Zoneamento Ecológico-Econômico (ZEE). Esses se baseiam em mapas geoambientais (geomorfologia, solos e geologia) refinados e compatibilizados com uso de imagens de satélite como "âncora" na delimitação das UTB's. Essas são resultantes do cruzamento por análise booleana desses mapas geoambientais com 
aqueles de classificação de uso e cobertura da terra baseada em imagens de satélite (CREPANI et al., 2001). Outra aplicação de mapeamento, conforme a abordagem geossistêmica de Bertrand e Bertrand (2002), foi realizado por Freitas (2006) e Freitas e Carvalho (2009) no nordeste brasileiro, em escala de semi-detalhe, com a identificação ao nível de geossistemas e de geofácies com a caracterização da dinâmica de uso e cobertura da terra numa série temporal. Princípios de hierarquização da paisagem em hólons foram utilizados para o mapeamento de geossistemas em uma bacia hidrográfica na região Sudeste do Brasil, citado por Cunha e Freitas (2004), baseados em Monteiro (2001).

Nessa área de geotecnologias, o desenvolvimento de uma nova abordagem denominada Análise de Imagens Orientada a Objetos Geográficos (GEOBIA), um sistema baseado no conhecimento do especialista que integra SIG e SR, trouxe contribuições em diversos tipos de mapeamentos (BLASCHKE, 2010). Esta permite classificar uma série de dados matriciais a partir de objetos vetoriais gerados por técnicas como segmentação multi-resolução. Isso substitui a abordagem pixel-a-pixel, predominante na maioria dos softwares de Processamento Digital de Imagens (PDI), conforme citado por (BLASCHKE, 2010). A partir da incorporação do conhecimento do especialista, este sistema combina funções complementares de PDI e de SIG através da implementação de regras de decisão nebulosas (fuzzy), além da incorporação de atributos espectrais, espaciais, texturais e temáticos para a classificação de imagens de alta e média resolução. Isso permite a detecção de atributos diversos em diferentes áreas (e.g., geomorfologia, Ecologia da Paisagem, agricultura, urbanismo, etc.). A principal característica da GEOBIA que a aproxima do mapeamento integrado da paisagem é a segmentação multi-resolução e sua estrutura hierárquica que se aproximam da noção de hólon (KOESTLER, 1978), como apontado por Lang (2005). Por conseguinte, Lang (2008) propõe o conceito de geon, baseado em GEOBIA, que é uma arquitetura integradora para regionalização, análise e monitoramento, com base em variáveis espaciais, fornecendo uma pluralidade de soluções orientada ao suporte de políticas públicas devido à inerente complexidade da paisagem e dos fenômenos do ambiente real. Podem ser notadas similaridades entre esse conceito de geon e a abordagem geossistêmica, tanto do ponto de vista metodológico como ferramenta de regionalização, análise e monitoramento, destinado ao suporte na tomada de decisão no planejamento territorial que requer um tratamento integrado da paisagem.

\section{ÁREA DE ESTUDO}

A área estudada (Figura 1) é uma região que engloba 18 municípios localizados no Alto da Bacia do Rio Uruguai, nos limites estaduais brasileiros do Rio Grande do Sul e Santa Catarina, com uma área aproximada de $12.000 \mathrm{~km}^{2}$. É uma área típica do Planalto Basáltico ou Meridional com altitudes entre 600 e 1200 metros, no domínio fitogeográfico da Floresta Ombrófila Mista (conhecida como Floresta de Araucárias) e dos campos sulinos nativos, com suas dinâmicas próprias de ocupação das terras, sobre variados agrupamentos de solos, desde latossolos e nitossolos até neossolos litólicos. O clima é subtropical (predominante $\mathrm{Cfa}$ ) com quatro estações bem definidas, grande variação térmica e chuvas bem distribuídas ao longo do ano, além da ocorrência de geadas, em especial nos campos nativos dos altos platôs, onde é classificado como tipo $\mathrm{Cfb}$. 
Figura 1. Localização da área de estudo e respectivos municípios que a compõem.

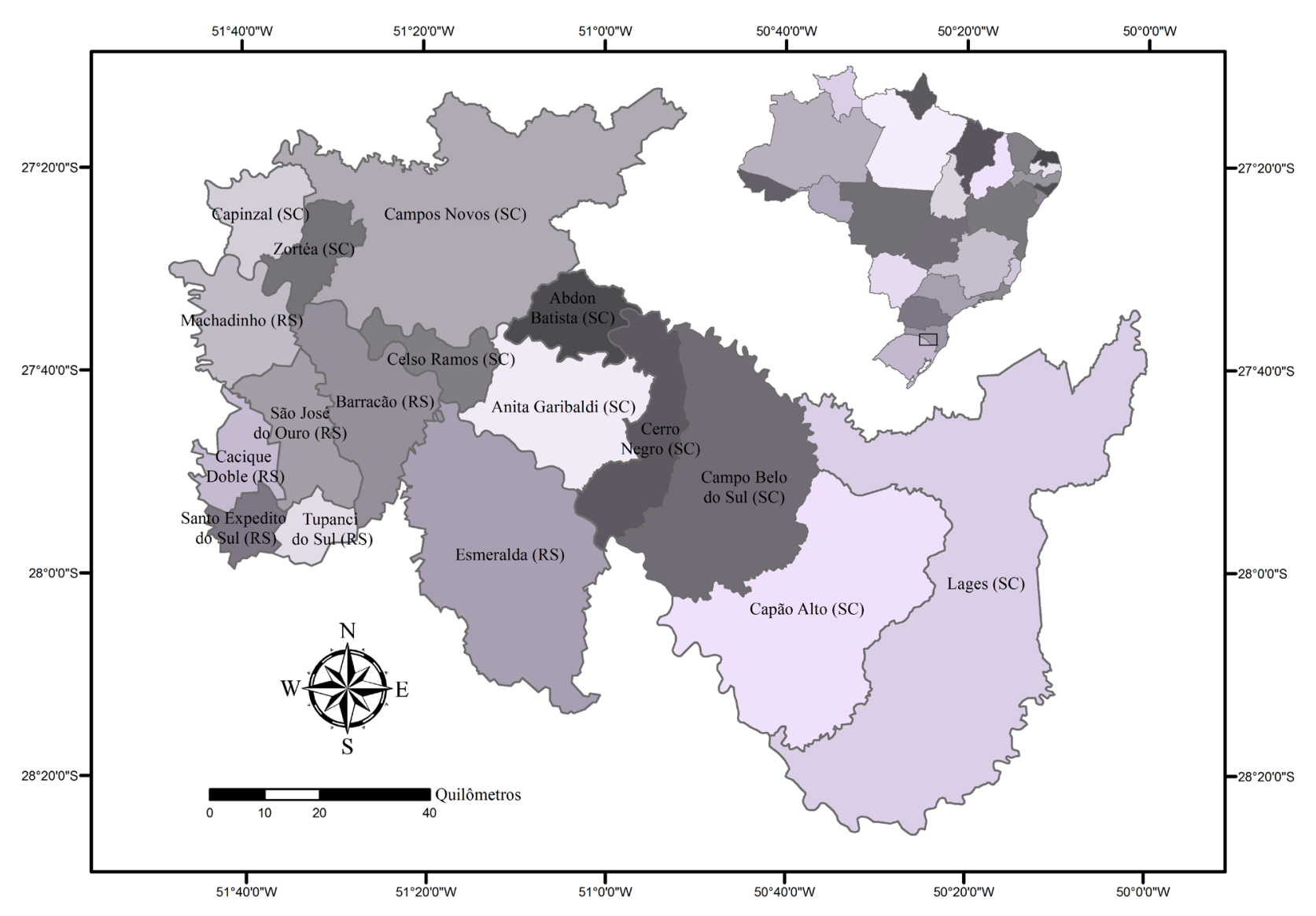

Elaboração dos autores.

\section{METODOLOGIA}

De uma forma sumarizada a abordagem metodológica é composta por três etapas principais: a) organização e processamento das variáveis paisagísticas em ambiente de SIG e de GEOBIA; b) zoneamento hierárquico em geons da paisagem e unidades de planejamento da paisagem; c) análise multivariada das UPP's resultantes com a definição de dois níveis hierárquicos (hólons) da paisagem. Essas etapas estão descritas a seguir.

\section{Organização das variáveis paisagísticas}

Foram empregadas no presente trabalho as variáveis físicas (atributos geomorfométricos), ecológicas (métricas de paisagem) e sociais (dados censitários), inicialmente processadas e organizadas em ambiente de SIG. Posteriormente, associadas com mapeamentos temáticos geoambientais (geomorfologia, geologia e solos) em diferentes escalas e formatos para a geração do mapeamento integrado da paisagem (Tabela 1). No caso, utilizou-se uma padronização cartográfica em na projeção UTM, datum WGS-84, zona 22-Sul. 
Tabela 1. Variáveis físicas, ecológicas e sociais definidas como entrada ao mapeamento integrado da paisagem.

\begin{tabular}{|c|c|c|}
\hline Variáveis & Equações* & Unidades/Tipo \\
\hline Geomorfologia (4 unidades) & & Categórica (binária) \\
\hline Solos (7 grupos) & & Categórica (binária) \\
\hline Uso e cobertura da terra (7 classes) & & $\%$ de área da classe \\
\hline Elevação & & Metros \\
\hline Declividade & & Graus \\
\hline Relevo local & & Metros \\
\hline Rugosidade superficial & & - \\
\hline Área de mancha & & Metros quadrados \\
\hline Número de manchas & & Contagem \\
\hline Densidade de manchas & $(\mathrm{NP} / \mathrm{TLA})(100)$ & Contagemt $/ \mathrm{Km}^{2}$ \\
\hline Densidade de bordas & TEL/TLA & Metros/ $\mathrm{Km}^{2}$ \\
\hline Índice de maior mancha (LPI) & ALP/TLA & Metros $^{2}$ \\
\hline Índice de dimensão fractal & $2 \log (p) / \log (a)$ & - \\
\hline Índice de forma & $p / 2 \sqrt{\pi a}$ & - \\
\hline Razão perímetro-área & $p / a$ & - \\
\hline Tamanho de mancha efetivo (MESH) & $\sum a^{2} / T L A \sum a^{2} / T L A$ & Hectares \\
\hline Índice de retalhamento (SPLIT) & $T L A / \sum a^{2} T L A / \sum a^{2}$ & - \\
\hline Renda nominal & & Reais (R\$) \\
\hline Renda média & & Reais ( $\mathrm{R} \$)$ \\
\hline Média de anos de estudo & & Contagem \\
\hline Taxa de alfabetização & & $\%$ \\
\hline Densidade populacional & & População/Km² \\
\hline Razão de dependência & & $\%$ \\
\hline Número médio de residentes por domicílio & & Contagem \\
\hline População menor de 15 anos de idade & & $\%$ \\
\hline População entre 15 e 64 anos de idade & & $\%$ \\
\hline População acima de 64 anos de idade & & $\%$ \\
\hline
\end{tabular}

* Abreviaturas: NP é o número de manchas, TLA é a área total de cada unidade de paisagem, TEL é o comprimento total das bordas, ALP é a área da maior mancha da unidade de paisagem, $p$ é o perímetro e $a$ é a área de cada fragmento de cobertura vegetal. Org. dos autores. 
As variáveis geomorfométricas (elevação, declividade e relevo sombreado) utilizadas nesse trabalho foram baseadas em dados do Projeto Topodata (VALERIANO; ROSSETI, 2011), que consiste em Modelo Digital de Elevação (MDE) do Shuttle Radar Topographic Mission (SRTM) refinado de 3" para 1" (em torno de 30 metros) com base em tratamento geoestatístico, além de produtos derivados deste. Foram ainda geradas com base neste produto duas outras variáveis geomorfométricas: a) relevo local baseada na operação de diferença entre duas janelas móveis de tamanho 7x7 pixels de máximos e de mínimos locais do MDE (EVANS, 1972); b) rugosidade superficial baseada numa janela móvel $7 \times 7$ de desvio-padrão da declividade normalizado de 0 a 1 (GROHMANN et al., 2011).

A classificação multitemporal de uso e cobertura da terra foi obtida de imagens Landsat-TM dos anos de 2002 e 2008, com resolução espacial de 30 metros e bandas originais nas faixas do visível, infravermelho próximo e médio. Essas imagens foram tratadas e classificadas por técnicas de Análise de Componentes Principais (ACP), de modelo linear de mistura espectral (MLME) e GEOBIA com segmentação multi-resolução e uso de regras hierárquicas baseadas em funções de pertinência nebulosa (fuzzy membership functions), descritas em Freitas e Santos (2012). Na classificação foram consideradas as seguintes classes: a) Floresta Ombrófila Mista (FOM) em estágios avançado e médio de sucessão natural; b) Campo nativo da serra; c) Silvicultura; d) Agricultura familiar de semi-subsistência, um sistema tradicional de uso da terra heterogêneo com a formação de mosaicos de pastagens, atividades agrícolas, silvicultura e matas em regeneração de pequeno porte; e) Agricultura de grande porte, definidas por atividades agrícolas intensivas de alta mecanização e uso de tecnologia para a produção de soja, trigo e milho em especial; f) Urbano; g) Corpos d'água.

As métricas da paisagem foram calculadas em ambiente de SIG através de scripts usando apenas aos fragmentos remanescentes de cobertura vegetal (floresta e campo nativo), como indicador da estrutura e grau de conservação da paisagem. O cálculo das métricas da paisagem foi gerado sobre estrutura de informação vetorial de manchas de cobertura vegetal no nível da paisagem (landscape level), utilizando as unidades de paisagem (UPP's) como nível de agregação da paisagem, de acordo com as formulações de McGarigal e Marks (1995) e de Lang e Blaschke (2009). Todas estas métricas calculadas individualmente para cada mancha foram usadas como métricas no nível da paisagem pela aplicação da operação de SIG de estatísticas zonais como média, desvio-padrão e amplitude em cada unidade de paisagem.

Por sua vez, os dados censitários do ano 2000 (IBGE, 2000), bem como os setores censitários rurais e urbanos, foram devidamente processados com adequação de projeção cartográfica e de topologia. Os mapas geoambientais foram georreferenciados e usados para visualização e preenchimento da tabela de atributos, de acordo com adaptações das legendas das diversas fontes e escalas usadas. No caso da geomorfologia, utilizaram-se na porção do estado do Rio Grande do Sul as folhas do mapeamento geomorfológico do IBGE (2005) na escala 1:250.000, enquanto em Santa Catarina foram usadas folhas do RADAMBRASIL (1986) na escala 1:1.000.000. Em relação aos solos foi utilizado no Rio Grande do Sul folhas do RADAMBRASIL (1986) na escala 1:1.000.00 e em Santa Catarina o mapeamento pedológico na escala 1:250.000 (EMBRAPA, 2005). Nesse caso foi necessário realizar uma adaptação das legendas dos mapeamentos geomorfológico e pedológico com a definição de 4 unidades geomorfológicas e 7 grupos de associações de solos. As unidades geomorfológicas foram assim definidas: a) platôs côncavo-convexos suave-ondulados (GEOM-1), b) modelado côncavo-convexo de dissecação fraca a média (GEOM_2), c) modelado côncavo-convexo de dissecação média a forte (GEOM_3), d) modelado tabular de dissecação média a forte (GEOM_4). Já as associações de solos foram as correspondentes: a) cambissolos e neossolos litólicos (SOLOS_G1), b) cambissolos, nitossolos e neossolos litólicos (SOLOS_G2), c) nitossolos, cambissolos e neossolos litólicos (SOLOS_G3), d) nitossolos e latossolos (SOLOS_G4), e) cambissolos, latossolos e nitossolos (SOLOS_G5), f) latossolos, nitossolos e cambissolos (SOLOS_G6), g) latossolos (SOLOS_G7). 


\section{Estruturação do zoneamento hierárquica da paisagem}

O mapeamento integrado da paisagem da bacia do alto Rio Uruguai, de forma hierárquica, foi construído baseado no princípio de hólon de Koestler (1969) e que já foi também utilizado no mapeamento e definição de geossistemas por Monteiro (2001). No presente caso, foi empregado também na concepção de geon oriunda da análise orientada a objetos geográficos (GEOBIA) e relacionada com unidades produzidas em ambiente SIG com informações geoespaciais, ligadas ao planejamento territorial e à tomada de decisões de cunho espacial (Lang, 2008). Duas hierarquias principais foram estabelecidas no mapeamento integrado da paisagem: a) Geons da Paisagem, nível superior baseado na segmentação multi-resolução e na interpretação visual de atributos físicos (geomorfométricos) e de mapeamentos geoambientais; b) Unidades de Planejamento da Paisagem (UPP's), nível inferior resultado da compatibilização dos Geons da Paisagem com as unidades sociais (setores censitários rurais), posteriormente classificadas em dois níveis hierárquicos superiores (hólons).

\section{Geons da Paisagem}

Os geons da paisagem foram baseados na segmentação multi-resolução de dados geomorfométricos (MDE, rugosidade superficial, relevo local e relevo sombreado) em ambiente de GEOBIA. Os parâmetros da segmentação multi-resolução de forma (shape) e compacidade (compactness) foram fixados em 0.5 , enquanto o parâmetro de escala (scale) variou numa amplitude de 50 até 300 . Estes níveis de segmentação (Figura 2) foram exportados para ambiente SIG onde foram analisados e agrupados de forma interativa de acordo com a interpretação visual baseada em mapeamentos geomorfológico e pedológico (RADAMBRASIL, 1986; EMBRAPA, 2005), MDE e relevo sombreado.

Figura 2. Exemplos de níveis de segmentação multi-resolução baseados em dados geomorfométricos.

A) Nível 50

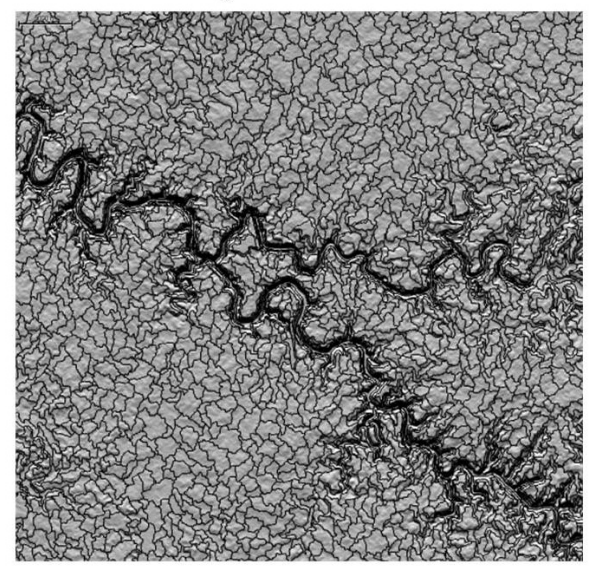

B) Nível 300

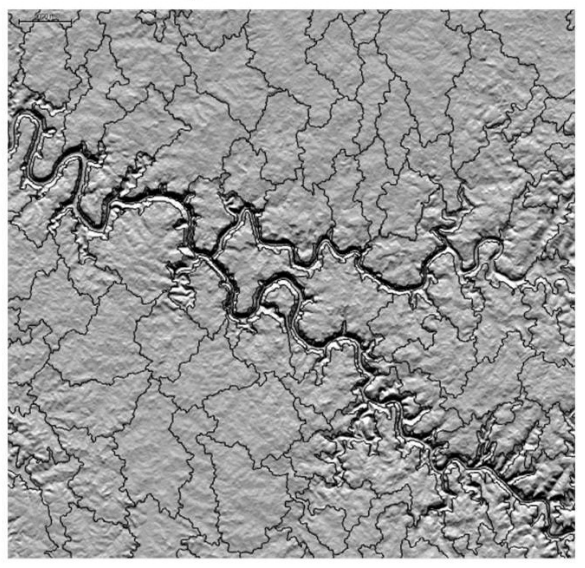

Fonte: RADAMBRASIL, 1986; EMBRAPA, 2005, Adaptado pelos autores.

Esta abordagem metodológica está relacionada com o processo de refinamento escalar utilizado pelo projeto de Zoneamento Ecológico-Econômico (ZEE) (CREPANI et al., 2001) na delimitação das denominadas unidades territoriais básicas. Outros trabalhos nessa linha investigativa também fizeram suas adequações metodológicas, como o de Freitas e Carvalho (2009), que se basearam na edição vetorial sobre base de dados em SIG para o mapeamento de geossistemas e geofácies em área do Nordeste brasileiro.
No presente caso, o processo foi semi-automatizado, sem a necessidade de o especialista realizar edições vetoriais, apenas agrupando de forma interativa os níveis de segmentação gerados por GEOBIA. Contudo, este processo continua baseado na interpretação da paisagem, onde o usuário deve buscar as similaridade e correlações espaciais de dados físicos e ecológicos com o suporte de composições coloridas de imagens de satélite, de MDE e produtos derivados. 
b) Unidades de Planejamento da Paisagem

A delimitação das UPP's foi gerada em ambiente de SIG através da intersecção entre os "geons da paisagem" e os setores censitários rurais, seguida de uma operação de compatibilização baseada na interpretação dos padrões da paisagem a partir da classificação de uso e cobertura da terra do ano de 2008 (Figura 3). Esta compatibilização foi fundamentada nos setores censitários rurais, disponibilizados por IBGE (2000), considerando-se ainda o problema das unidades de área modificável (Modifiable Area Units Problem MAUP) e de falácia ecológica (OPENSHAW, 1984; WRIGLEY et al., 1996), inerentes ao se lidar com dados geoespaciais de diferentes naturezas e formas de delimitação do espaço. Os procedimentos empregados em tal compatibilização foram: a) agregação de pequenos setores censitários rurais representando sedes de distritos rurais nos setores maiores que os englobam; b) divisão do setor censitário rural da sede do município de Lages (uma agregação de 172 setores censitários urbanos) de acordo com características rurais ou urbanas dos setores periféricos; bem como a correspondente adequação das informações censitárias; c) em poucos casos, devido a grandes diferenças paisagísticas, houve alguma necessidade de divisão do setor censitário rural original.

Figura 3. Diagramação de etapas para a geração de UPP's baseadas em geons da paisagem da Bacia do Alto Rio Uruguai compatibilizados com setores censitários.
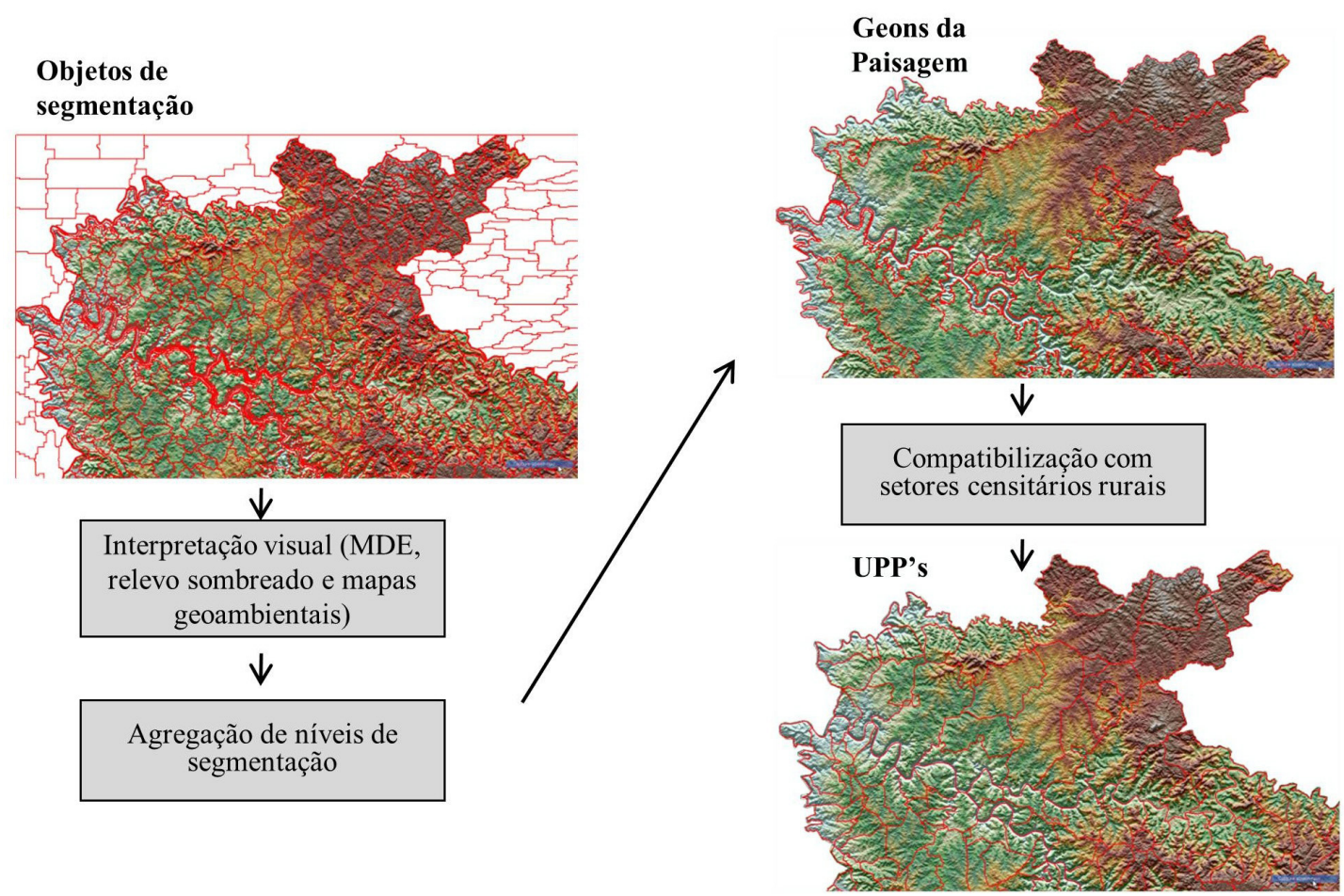

Elaboração dos autores.

c) Análise multivariada e agrupamentos de UPP's

Uma análise multivariada foi realizada com as UPP's geradas para encontrar possíveis padrões paisagísticos, considerando diferentes graus de homogeneidade e dissimilaridade. Esta necessidade de avaliação estatística do quanto às unidades de paisagem mapeadas apresentam diferenças entre si foi preconizada por Silva et al. (2007) com o uso da técnica de análise de agrupamento (Cluster Analysis). Neste caso, foram utilizadas as variáveis físicas, ecológicas e sociais (Tabela 1), introduzindo também variáveis categóricas (classes de solos, unidades geomorfológicas e litológicas) em conjunto com variáveis contínuas geomorfométricas, de métricas de paisagem e censitárias.

Devido ao uso conjugado de variáveis categóricas e contínuas, métodos adaptados daqueles 
tradicionais tiveram que ser empregados, neste caso o algoritmo de auto-agrupamento Two Step Cluster (ZHANG et al., 1996; CHIU et al., 2001) e a Análise de Correspondência Canônica (Canonical Correspondence Analysis - CCA) (LEPŠ; SMILAUER, 2003). O primeiro algoritmo foi utilizado para a geração de grupos automáticos de acordo com testes de significância de qui-quadrado para as variáveis categóricas e de Análise da Variância (ANOVA) para as variáveis contínuas. $\mathrm{O}$ resultado preliminar foi a definição automática de três agrupamentos, os quais foram posteriormente ajustados pela interpretação do analista para 5 grupos de UPP's, com o apoio da técnica de auto-agrupamento (flexibilizada pelo uso de parâmetros, como o número de grupos a serem gerados). Já a Análise de Correspondência Canônica (CCA) foi realizada com os dois agrupamentos gerados na primeira etapa para checar a validade de ambos e gerar uma análise de ordenamento entre os hólons mapeados (considerados como espécies) e as variáveis ambientais utilizadas neste trabalho. Para tal, foram produzidos diagramas de ordenação com as variáveis significantes, de acordo com uma seleção stepwise (manual forward stepwise selection) baseada no teste randômico Monte Carlo do tipo- $F(\alpha=0.05)$.

\section{RESULTADOS}

\section{Análise multivariada das Unidades de Planejamento da Paisagem - UPP's}

O resultado final das UPP's pode ser considerado uma espécie de banco de dados da paisagem ou Modelo Digital da Paisagem (LANG; BLASCHKE, 2009), que se apresenta na forma de unidades compatibilizadas com setores censitários, adotada por ser a unidade mínima de divulgação de dados sociais pelo órgão de pesquisa governamental. Estas apresentam concordância com os limites administrativos, de modo especial em nível local (e.g., distritos rurais, bairros urbanos, terras indígenas e outras), tendo como característica a potencialidade de integrar de forma sintética um conjunto de informações espaciais intrínsecas ao subsídio na tomada de decisões e na implementação de políticas públicas relacionadas com o planejamento territorial. A catalogação em um SIG das variáveis físicas, ecológicas e sociais permite a geração de múltiplas análises de cunhos temáticos interdisciplinares e multidisciplinares, sob a mesma base de divisão do espaço.

Do ponto de vista dos resultados principais desse estudo na bacia do Alto Rio Uruguai, aquele que expressa o agrupamento em dois níveis hierárquicos (Figura 4) nos permitiu uma interpretação escalar das características paisagísticas dominantes e do quadro geral de correlações que regem os mosaicos de paisagem mapeados. Em relação ao nível hierárquico superior (3 hólons) este representa: a) áreas dominadas pela urbanização, agricultura de grande porte e processo de expansão da silvicultura (hólon A1); b) áreas relacionadas às práticas da agricultura familiar mista de semi-subsistência e às maiores manchas de florestas remanescentes (hólon A2); áreas com predomínio de campos nativos com a penetração de silvicultura, agricultura familiar e de grande porte em algumas partes (hólon A3). Já no nível inferior (5 hólons), ocorreu: a) a divisão do hólon $\mathrm{A} 1$ em relação às áreas de agricultura de grande porte (hólon $\mathrm{B} 1$ ) e de processos de urbanização e de expansão da silvicultura (hólon B5); b) o remodelamento do hólon A2 de agricultura mista de cunho familiar (hólon B2); c) a divisão do hólon $\mathrm{A} 3$ em áreas com expansão de atividades agrícolas (hólon B3) e uma área conservada de campos nativos (hólon B4).

Os perfis geoambientais (Figura 4) permitem uma visualização da relação entre o suporte geoecológico (compartimentos topográficos, modelados do relevo associados a estes e agrupamentos de solos) e os sistemas e tipos de uso e cobertura da terra que os ocupam. O primeiro perfil geoambiental (A-B) mostra os padrões de paisagem relacionados aos hólons $\mathrm{B} 1 \mathrm{e} \mathrm{B} 2$, bem como as áreas de contato entre estas unidades que representam os dois padrões de paisagem agrícola (tradicional colonial familiar x moderno intensivo de grande porte). O segundo perfil geoambiental (C-D) apresenta os padrões da paisagem dos hólons B1, B2, B3 e B4, adicionando aos dois padrões vistos no perfil anterior os hólons de campos nativos com pecuária extensiva tradicional e também com a penetração de usos de silvicultura e agricultura familiar e de grande porte. O terceiro perfil geoambiental (E-F) revela os padrões da paisagem dos hólons $\mathrm{B} 1, \mathrm{~B} 2$, B3 e B5, adicionando aos padrões vistos anteriormente o hólon urbano-industrial com expansão da silvicultura relacionada à indústria da celulose. 
Figura 4. Os dois níveis hierárquicos (hólons) gerados a partir da análise de agrupamento das variáveis socioambientais das UPP's e três perfis geoambientais (transectos A-B, C-D e E-F).
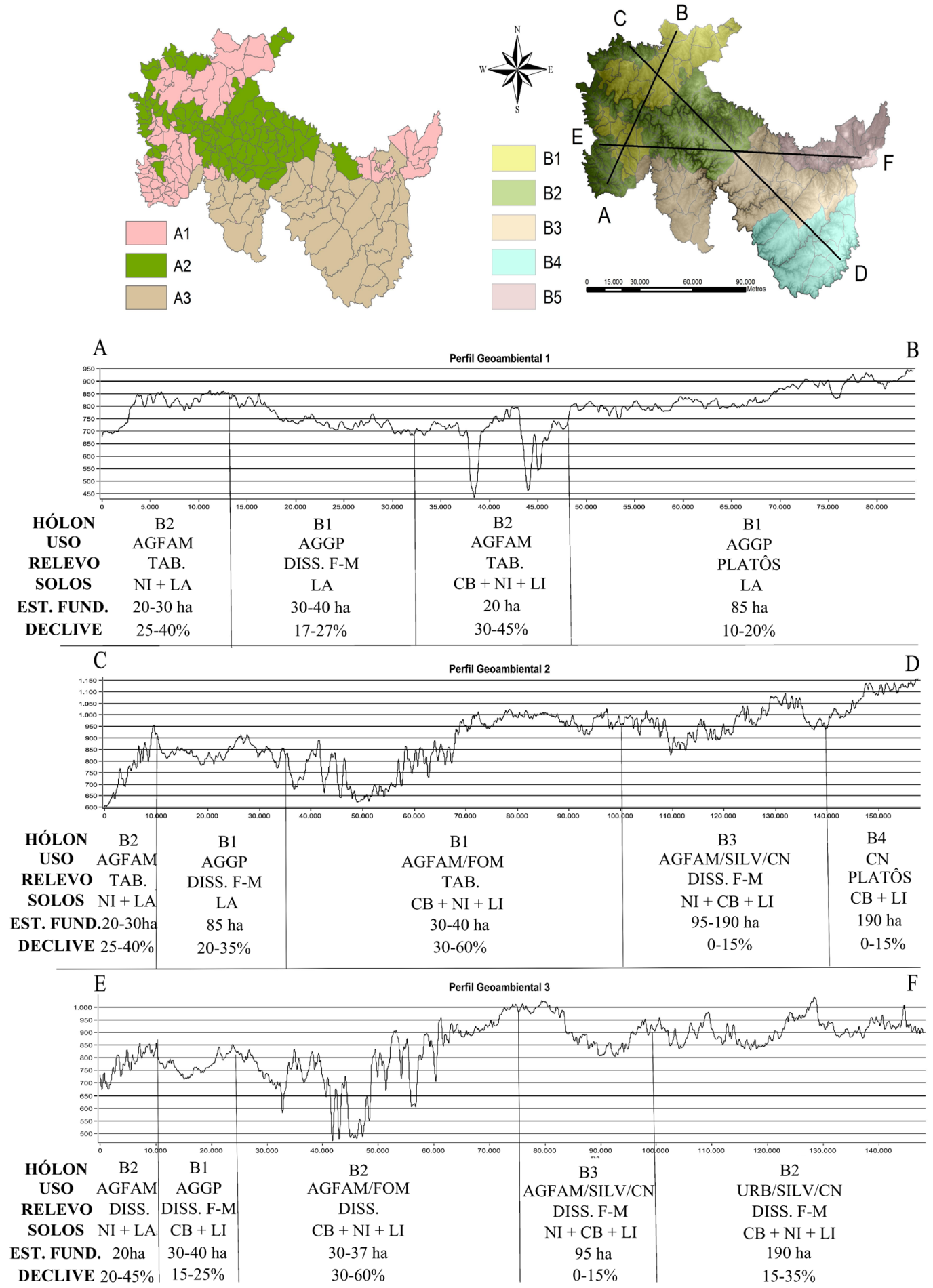

Abreviaturas: agricultura familiar (AGFAM), agricultura de grande porte (AGGP), floresta (FOM), silvicultura (SILV), campo nativo (CN), urbano (URB), modelado tabular de dissecação média-forte (TAB.), modelado côncavo-convexo de dissecação média a forte (DISS. F-M), platôs côncavo-convexos suave-ondulados (PLATÔS), modelado côncavo-convexo de dissecação média-forte (DISS.), latossolos (LA), nitossolos (NI), cambissolos (CB), neossolos litólicos (LI). Elaboração dos autores. 
Outro importante resultado advém da análise do diagrama de ordenamento da CCA (Figura 5) que ilustra o comportamento das variáveis paisagísticas significantes para a diferenciação das unidades hierárquicas da paisagem (hólons) mapeadas, com as variáveis paisagísticas independentes explicando em torno de $75 \%$ a variância dos dados. Tal diagrama diferencia bem os três hólons superiores e os hólons relacionados no nível inferior, podendo, através das suas posições em zonas bem identificáveis, visualizar as distintas interações entre as variáveis nas zonas agrícolas de grande porte e urbano-agrícolas (hólons A1, B1 e B5), zonas de agricultura familiar colonial de pequena propriedade (hólons A2 e B2) e as zonas de campos nativos com pecuária extensiva tradicional e avanço de outros usos agrícolas e de silvicultura (hólons A3, B3 e B4).

Figura 5. Diagrama de ordenamento gerado pela CCA.

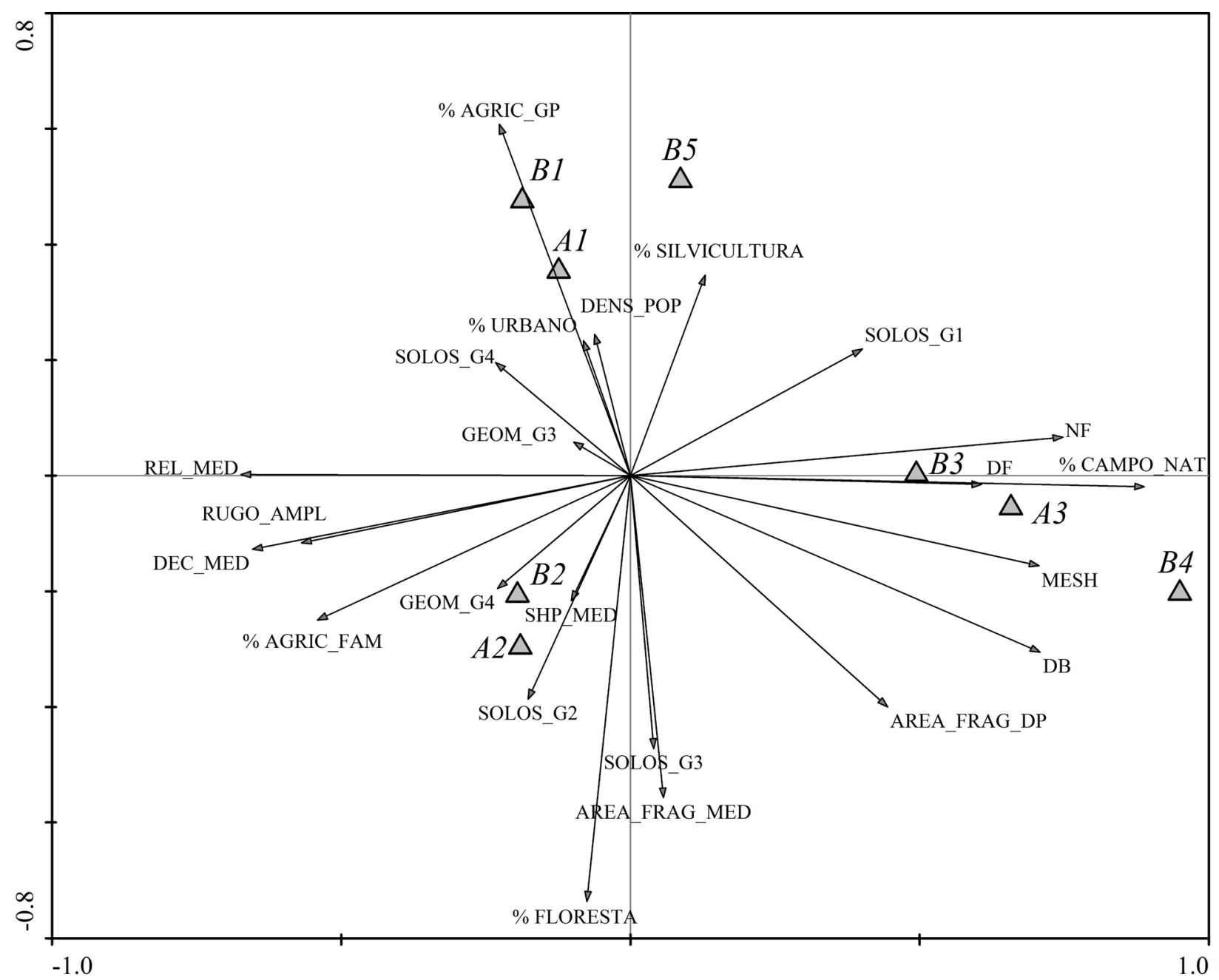

Abreviaturas: floresta (\% FLORESTA), campo nativo (\% CAMPO_NAT), agricultura de grande porte (\% AGRIC_GP), silvicultura (\% SILVICULTURA), agricultura familiar ((\% AGRIC_FAM), urbano (\% URBANO), modelado côncavo-convexo de dissecação média a forte (GEOM_3), modelado tabular de dissecação média a forte (GEOM_4), cambissolos e neossolos litólicos (SOLOS_G1), cambissolos, nitossolos e neossolos litólicos (SOLOS_G2), nitossolos, cambissolos e neossolos litólicos (SOLOS G3), nitossolos e latossolos (SOLOS G4), média e desvio-padrão da área de mancha (AREA_FRAG_MED e AREA_FRAG_DP), densidade de bordas (DB), média do índice de forma (SHP_MED), número de manchas (NF), densidade de fragmentos (DF), tamanho de mancha efetivo (MESH), média do relevo local (REL_MED), amplitude da rugosidade superficial (RUGO_AMPL) e densidade populacional (DENS_POP). Elaboração dos autores. 
As correlações positivas do hólon A1 com os hólons B1 e B5 mostram estreita relação entre eles (Figura 5), razão da ocorrência comum de elevadas porcentagens de agricultura de grande porte, silvicultura e urbanização nessas regiões estudadas, situadas em solos dominantes com grupos de latossolos e geomorfologia de platôs altos com relevo suave; além de maior densidade populacional. As correlações negativas mais fortes ocorrem com a porcentagem de floresta e tamanho médio de mancha de cobertura vegetal, o que revela a menor taxa de conservação do ambiente natural nestas áreas de intenso uso agrícola, industrial e urbano. Esta situação se reflete na distinção entre o hólon B1, no entorno de Campos Novos-SC e de Barracão-RS, que é uma área de agricultura de grande porte consolidada sobre solos desenvolvidos e relevo suave, oriunda de uma política de fronteira agrícola moderna, e o hólon B5, no entorno de Lages-SC, que é o maior centro urbano-industrial da área, com destaque para a indústria de celulose e de serviços, que geram suporte ao fenômeno da concentração populacional e da expansão da silvicultura.

Por sua vez, os hólons A2 e B2 apresentam posição semelhante no diagrama de ordenação e fatores bastante diferenciados dos demais hólons nos dois níveis hierárquicos. As principais correlações positivas foram encontradas com a geomorfologia mais movimentada do modelado tabular de dissecação média a forte (declividade média e relevo local médio, além de amplitude da rugosidade superficial), métricas da paisagem indicadoras de áreas mais conservadas (índice de forma médio e área de mancha média), solos predominantes rasos (neossolos litólicos) com manchas associadas de solos férteis (nitossolos), além da maior porcentagem de floresta e agricultura familiar que ainda ocupam estas áreas. Tais condições são relacionadas com a colonização europeia e o gênero de vida relacionado com a agricultura familiar de pequena propriedade e destinadas à semi-subsistência. Esta maneira de ocupação das terras foi introduzida nos locais localizados nas serras e fundos de vale, em contraste com as áreas de solos agricultáveis nos altos platôs, que já pertenciam a grandes proprietários; hoje vivem em condição de pressão pelos centros de agricultura moderna típicos do hólon B1 (FURTADO, 1972; RIBEIRO, 1995). Apesar da pressão, estas áreas permanecem pelas potencialidades paisagísticas e culturais, as quais combinam com o sistema de uso da terra tradicional, mas que vêm apresentando ultimamente algumas transformações de caráter econômico-social, porém em ritmo mais lento do que das áreas urbano-industriais e de agricultura de grande porte dos hólons A1, B1 e B5.

Os hólons A3, B3 e B4 apresentam posição semelhante, contrastando com os dois tipos de hólons mencionados anteriormente. As principais correlações positivas encontradas foram com a porcentagem de campo nativo, métricas de paisagem (número e tamanho de manchas, e, por conseguinte, densidade de bordas), que expressam um bom estado de conservação ainda, na maior parte do campo nativo (em especial do hólon B4); os solos são em sua maioria rasos (neossolos litólicos) e o relevo local é negativamente correlacionado, representando os altos platôs de relevo suave dos campos de cima da serra, como são popularmente conhecidos. Tais áreas são de fato representativas da forma de ocupação mais antiga nos domínios sob influência do Alto Rio Uruguai, com tradicional pecuária extensiva em campos nativos, práticas essas que datam do século XVIII. A divisão da área em dois hólons no nível hierárquico inferior se deve às condições naturais e culturais mais conservadas do hólon B4, enquanto o hólon $\mathrm{B} 3$ é palco de um avanço de atividades agrícolas e de silvicultura com maior velocidade.

\section{CONCLUSÕES}

O zoneamento hierárquico da paisagem adotado neste trabalho apresenta a abordagem de GEOBIA como elemento-chave da integração de dados manipulados via SIG e SR, por ter: a) foco nas ferramentas baseadas no conhecimento do especialista e b) concepção hierárquica da estrutura baseada na técnica de segmentação multi-resolução.

A estrutura hierárquica proposta, baseada nos geons da paisagem e nas Unidades de Planejamento da Paisagem (UPP's), possibilita uma classificação das zonas hierárquicas mapeadas e a análise das principais correlações paisagísticas e características dos mosaicos de paisagem gerados pela análise multivariada de agrupamento (Cluster Analysis) e CCA. A análise das zonas hierárquicas mapeadas nessa região do Alto Rio Uruguai mostrou uma relação estreita destas com padrões de uso da terra herdados de distintos modos de ocupação da paisagem, mais ou menos tradicionais 
(zonas de pecuária extensiva, agricultura familiar colonial e agricultura intensiva). O nível hierárquico abaixo mostra características relacionadas ao ritmo e adaptação de atividades às condições locais de produção, como: a) divisão da zona agrícola-industrial entre áreas tipicamente agrícolas (ao redor de Campos Novos e de Barracão) e de áreas urbano-industriais (no entorno de Lages); b) remodelamento da zona de agricultura familiar de característica colonial; c) divisão da zona tradicional de pecuária extensiva em área bem conservada de campo nativo no sul de Lages (Coxilha Rica) e outra, em um mosaico derivado de atividades de agricultura familiar e de agricultura de grande porte, aliadas ainda ao avanço da silvicultura.

Em síntese, este aporte tecnológico aqui retratado ainda é pouco explorado, mas abre um horizonte de pesquisas e aplicações referentes aos interesses de mapeamento integrado da paisagem. Isso, por exemplo, em especial com a utilização de regras nebulosas (fuzzy) hierárquicas para a classificação de paisagens, fazendo inclusive uso de atributos topográficos, espaciais e texturais.

\section{REFERÊNCIAS}

BERTRAND, C.; BERTRAND, G. Une geographie traversière: l'environment à travers territoires et temporalités. Paris, Éditions Arguments, 2002.

BLASCHKE, T. Object based image analysis for remote sensing. ISPRS Journal of Photogrammetry and Remote Sensing, v.65, n.1, p.2-16, 2010.

CAMARGO, F. F.; FLORENZANO, T. G.; ALMEIDA, C. M.; OLIVEIRA, C. G. Geomorphological mapping using object-based analysis and ASTER DEM in the Paraíba do Sul Valley, Brazil. International Journal of Remote Sensing, v.30, p.6613-6620, 2009. DOI: http:// dx.doi.org/10.1080/01431160903111044

CHIU, T.; FANG, D. ; CHEN, J. ; WANG, Y. ; JERIS, C. A robust and scalable clustering algorithm for mixed type attributes in large database environment. In: SEVENTH ACM SIGKDD INTERNATIONAL CONFERENCE ON KNOWLEDGE DISCOVERY AND DATA MINING. San Francisco, 2001. Proceedings... San Francisco, ACM, 2001.
CHRISTIAN, C. S. The concept of land units and land systems. In: NINTH PACIFIC SCIENCE CONGRESS, Bangcok, 1958. Proceedings... Bangcok, Thailand, v.20, 1958.

CREPANI, E.; MEDEIROS, J. S.; HERNANDEZ FILHO, P.; FLORENZANO, T. G.; DUARTE, V.; BARBOSA, C. C. F. Sensoriamento remoto e geoprocessamento aplicados ao Zoneamento Ecológico-Econômico $e$ ao ordenamento territorial. São José dos Campos, Instituto Nacional de Pesquisas Espaciais, 2001.

CUNHA, S. B.; FREITAS, M. W. D. Geossistemas e gestão ambiental na bacia hidrográfica do rio São João-RJ. GEOgraphia (UFF), v. 6, n.12, p. 87-110, 2004.

EMBRAPA. Mapa de Solos do Estado de Santa Catarina (escala 1:250.000). Florianópolis, Embrapa, 2005.

EVANS, I. General geomorphometry, derivations of altitude and descriptive statistics. In: CHORLEY, R. (Ed.). Spatial analysis in Geomorphology. London, Methuen, 1972, p.17-90.

GROHMANN, C.; SMITH, M.; RICCOMINI, C. Multiscale analysis of topographic surface roughness in the Midland Valley, Scotland. IEEE Transactions on Geoscience and Remote Sensing, v.49, n.4, p.12001213, 2011.

FRANÇA, C.; ALVES, C.; FREITAS, M.; BERGAMASCHI, R.. Compatibilização dos bairros e unidades de planejamento com os setores censitários no Estado do Espírito Santo. Geografares, n.6, p.35-46, 2008.

FREITAS, M. W. D. Estudos integrados da paisagem: abordagens complexas do espaço geográfico para o desenvolvimento sustentável. In: TORRES, F.; DAGNinO, R.; OLIVEIRA JR., A. (Orgs.) Contribuições geográficas. Ubá, Ed. Geographica, 2009, p.327-390.

FREITAS, M. W. D.; CARVALHO, V. Uso de geotecnologias para o mapeamento integrado de paisagens no sertão pernambucano (NE - Brasil). Geografia. Rio Claro, v.34, n.3, p.537-558, 2009. 
FURTADO, C. Análise do "modelo" brasileiro. Rio de Janeiro, Civilização Brasileira, 1972, 122p.

IBGE. Censo demográfico. Rio de Janeiro, IBGE, 2000.

KOESTLER, A. Janus: a summing up. Richmond South, Hutchinson of Australia, 1978, 354p.

LANG, S. A utilização do conceito de totalidade (holismo) na geração de planos de segmentação regionalizados em conjuntos de imagens de altíssima resolução. In: BLASCHKE, T.; KUX, H. (org.). Sensoriamento Remoto e SIG avançados: novos sistemas sensores, métodos inovadores. São Paulo, Oficina de Textos, 2005, p.33-40.

LANG, S. Object-based image analysis for remote sensing applications: modeling reality - dealing with complexity. In: BLASCHKE, T.; LANG, S.; HAY, G. (Org.) Object-based image analysis: spatial concepts for knowledge driven remote sensing applications. Berlin, Springer-Verlag, 2008, p.3-27.

LANG, S.; BLASCHKE, T. Análise da paisagem com SIG. São Paulo: Oficina de Textos, 2009.

LEPŠ J.; SMILAUER P. Multivariate analysis of ecological data using CANOCO. Cambridge: Cambridge University Press, 2003.

MCGARIGAL, K.; MARKS, B. J. Fragstats: spatial pattern analysis program for quantifying landscape structure. Gen. Tech. Rep. PNW-GTR-351. Portland, OR, US Department of Agriculture, Forest Service, Pacific Northwest Research Station, 1995.

MONTEIRO, C. A. F. Geossistemas: a história de uma procura. São Paulo, Contexto, 2001.

OPENSHAW, S. Ecological fallacies and the analysis of areal census data. Environment and Planning A, London, v. 16, p.17-31, 1984.

RADAMBRASIL. Folha SH.22 Porto Alegre e parte das Folhas SH.21 Uruguaiana e SI.22 Lagoa Mirim: geologia, geomorfologia, pedologia, vegetação e uso potencial da terra. Rio de Janeiro: Ministério das Minas e Energia, 1986.
RIBEIRO, D. O povo brasileiro: a formação e o sentido do Brasil. São Paulo: Companhia das Letras, 1995, 470p.

SILVA, V. P. Paisagem: concepções, aspectos morfológicos e significados. Sociedade \& Natureza, v.19, n.1, p.199-215, 2007.

SILVA, J.; CARVALHO, J.; SANTOS, R.; FELGUEIRAS, C. Zoneamentos ambientais: quando uma unidade territorial pode ser considerada homogênea? Revista Brasileira de Cartografia, n.59, v.1, p.83-92, 2007.

SOCHAVA, V. B. O estudo de geossistemas. Métodos em questão, n.16, p.1-51, 1977.

TRICART, J.; JONGE, C. K. Ecogeography and rural management, London: Longman, 1992.

WRIGLEY, N.; HOLD, T.; STEEL, D.; TRANMER, $\mathrm{M}$. Analysing, modeling and resolving the ecological fallacy. In: LONGLEY, P; BATTY, M. (Ed.). Spatial analysis: modeling: in a GIS environment. Cambridge: Geoinformation International, 1996.

VALERIANO, M. M.; ROSSETTI, D. F. Topodata: brazilian full coverage refinement of SRTM data. $A p$ plied Geography, v.32, p.300-309, 2011. DOI: http:// dx.doi.org/10.1016/j.apgeog.2011.05.004

WU, J. Hierarchy and scaling: extrapolating information along a scaling ladder. Canadian Journal of Remote Sensing, v.25, n.4, p.367-380, 1999.

ZHANG, T.; RAMAKRISHNON, R.; LIVNY, M. BIRCH: an efficient data clustering method for very large databases. In: ACM SIGMOD CONFERENCE ON MANAGEMENT OF DATA. Montreal. Proceedings... Montreal, ACM, 1996.

ZONNEVELD, I. The land unit: a fundamental concept in landscape ecology, and its applications. Landscape Ecology, v.3, n.2, p.67-86, 1989. 